\title{
PRÁTICAS DE LEITURA DOS PROFESSORES INDÍGENAS KIRIRI CANTAGALO
}

\author{
Jucimar Pereira dos Santos
}

RESUMO: O presente texto é resultado de um trabalho em Nível de Mestrado, desenvolvido no Programa de Pós-Graduação em Crítica Cultural na Universidade do Estado da Bahia - UNEB, Campus II - Alagoinhas no período de 2010-2011, cujo objetivo foi investigar as práticas de leitura dos professores indígenas Kiriri Cantagalo do Ensino Fundamental ( $5^{\mathrm{a}}$ à $8^{\mathrm{a}}$ série) que atuam no Colégio Estadual Indígena Florentino Domingos de Andrade, Aldeia Araçás do Município de Banzaê, no estabelecimento da relação entre cultura, educação e leitura. Para o desenrolar da pesquisa foi utilizada a seguinte questão: as práticas de ensino de leitura desenvolvidas pelos professores indígenas Kiriri Cantagalo têm contribuído para o fortalecimento de sua cultura indígena? A pesquisa percorre justamente questões de encantamento sobre o que vem a ser a leitura em uma escola indígena do Nordeste da Bahia, em um contexto de suas lutas históricas, conquistas e questões delicadas, tais como o processo de retomada do Território Indígena Kiriri, que vem ocorrendo a partir da década de 1970, os seus projetos societários, o acesso a bens culturais, a preservação e fortalecimento da cultura indígena Kiriri.

PALAVRAS-CHAVE: Leitura. Práticas de leitura. Educação Escolar Indígena.

ABSTRACT: This text is the result of a Masters level, developed the graduate program in Cultural criticism at the University of the State of Bahia-UNEB, Campus II-Alagoinhas in the 2010-2011 period, whose goal was to investigate the reading practices of indigenous teachers from Cantagalo elementary school (5th to 8th grade) who work in Indigenous State College Florentino Domingos de Andrade Araças, village in the municipality of Banzaê, in the establishment of the relationship between culture, education and reading. For the conduct of the research was used to following question: reading teaching practices developed by indigenous teachers- from Kiriri Cantagalo have contributed to the strengthening of its indigenous culture? The survey shows precisely issues about what happens to be reading in a northeast Indian School of Bahia, in the context of their historical struggles, achievements and delicate issues, such as the process of resumption of Indian territory - which has taken place from the late 1970, their corporate projects, access to good cultural preservation and strengthening of indigenous culture Kiriri.

KEYWORDS: Reading-reading. Practice-Indigenous. School education.

\section{INTRODUÇÃO}

O interesse em desenvolver um projeto de pesquisa sobre as práticas de leitura dos professores indígenas Kiriri Cantagalo se deu a partir dos vários momentos de formação desses professores, dos quais o pesquisador participou, motivado pelos 
materiais didáticos específicos que foram produzidos ao longo da $1^{\text {a }}$ Turma do Magistério Indígena da Bahia e, principalmente, observando a forma como tais professores desejavam estudar, especificamente, as questões relacionadas à leitura.

Historicamente, a Comunidade Indígena Kiriri é originária do Aldeamento Saco dos Morcegos, fundada pelos padres jesuítas por volta da metade do Século XVII. A presença de não índios fez com que os índios passassem a viver em pequenas áreas trabalhando para os fazendeiros locais. Plantavam um pouco de cada coisa para sobreviver e as casas eram de palha. Com a chegada do Serviço de Proteção ao Índio SPI, na Aldeia de Mirandela, no ano de 1949, os índios Kiriri iniciaram a reivindicação de suas terras. A luta foi iniciada pelos índios Josias e Emiliano, que, na época, eram chamados de Capitães. No ano de 1972, elegeram o índio Lázaro Gonzaga para ser Cacique. Em 1981, iniciou-se o processo para demarcar a área a ser homologada. Iniciou-se, então, uma grande luta entre os índios Kiriri e os posseiros que viviam no Território Kiriri. No dia 15 de janeiro de 1990, os índios Kiriri tiveram a sua área homologada através do Decreto Presidencial nº 98.828/1990. (FUNAI, 2010)

O nome Cantagalo, segundo os anciões da Aldeia, deve-se ao fato de que, antigamente, os índios mais velhos ouviam um galo cantar lá no meio de uma grota, que é uma grande abertura na terra parecida com uma gruta, onde não existia nada, só a serra. Eles diziam que era o galo-bicho. Por causa desse galo, se deu o nome de Comunidade Cantagalo, sendo, mais tarde, após a divisão do Povo Kiriri, denominada Kiriri Cantagalo.

Durante os processos de desenvolvimento da pesquisa, questões importantes são postas, denotando a relevância desse trabalho, compreendendo a leitura como algo de sentido amplo, ou seja, as práticas de leitura partiam sempre da leitura de mundo, das vivências do dia-a-dia, para então ir trazendo para a escola, à sala de aula, a leitura da palavra, fazendo essas relações ricas de significados. Dessa forma, é a leitura da vida que move todo o processo de vivência dos alunos indígenas com as outras leituras; aqui entram as questões relacionadas aos contos, lendas, causos, várias histórias dos mais velhos, histórias cheias de mistério e de encantamento.

Durante a pesquisa, as inquietações, desafios e obstáculos no que concerne ao trabalho de leitura no contexto da educação escolar indígena Kiriri Cantagalo, observando como essas práticas são desenvolvidas, as lutas presentes e as formas como 
esses professores vêm desenvolvendo as suas práticas de leitura apontam para um caminhar profícuo, entendido como o entremear de sua cultura, suas formas de viver e sobreviver.

\section{ALGUMAS CONSIDERAÇÕES SOBRE LEITURA NA ESCOLA INDÍGENA}

A oportunidade de refletir sobre as questões de leitura a partir de um trabalho de pesquisa que aborde práticas de leitura realizadas por professores e professoras indígenas no contexto do semiárido da Bahia é um trabalho de vanguarda, desafiador, pois é uma postura de construção e desconstrução, diálogos entre a literatura ocidental e as questões da cultura indígena, rompendo paradigmas hegemônicos, e instituindo, dessa forma, a grandeza de experiências encontradas no contexto da educação escolar indígena, uma educação diferenciada, específica, comunitária.

Para iniciar tal empreitada, irei partir das reflexões acerca da leitura de forma geral para, em seguida, trazer as questões pertinentes às práticas de leitura em contextos educacionais indígenas, mais especificamente na educação escolar Kiriri Cantagalo. De acordo com Perrotti (2007, p.2) a leitura é uma experiência interior magnífica, uma forma importantíssima e insubstituível de sentidos, de significados, um complexo e esplêndido jogo entre o texto e o leitor.

Esse jogo entre o texto e o leitor vai sendo descortinado de várias formas e, nessas várias formas, a leitura vai sendo feita, vai sendo construída, não somente na presença e na existência de um livro, mas de outros suportes: a participação nas reuniões gerais da comunidade, nos toantes da zabumba, na dança do Toré, documentários, relatórios, atas de reuniões, fotografias, mapas, relatos orais e escritos.

Sendo, então, a leitura essa experiência interior magnífica, citando novamente Perrotti (2007),

"É preciso reconhecer a leitura que conta, aquela que efetivamente toca, toma agarra, essa constitui um espaço/tempo interior esplêndido, com características distintas do mundo físico, concreto, objetivo, em que nos movemos: memória, imaginação, pensamento, afetos, emoções, sensibilidade são algumas das forças mobilizadoras dessa leitura que configura uma experiência única e inigualável. Se gostamos, se somos arrebatados pelo texto, a viagem interna é grande e, como se diz com frequência, esquecemos o mundo". (PERROTTI, 2007, p.2) 
Leitura, vista nesta ótica, como uma viagem, que acontece em um espaço/tempo, que envolve memória, imaginação, pensamento, afetos, emoções e sensibilidades... Quem não se lembra das histórias ouvidas na infância, vivas ainda em nossas memórias, nas viagens literárias que sempre se fizeram presentes em nossas vidas? É essa concepção de leitura, como algo que busca dentro de cada um de nós essas experiências, nos envolve de desejos e emoções, sentimentos de saudade e de experiências tão diferentes entre si, na subjetividade de cada um.

Dessa forma, a leitura aqui se apresenta como algo livre, que acontece na vida da gente, sem se preocupar com o objetivo de fazê-la num prestar de contas, quando essa é realizada no espaço escolar. Leituras e leituras que são realizadas no silêncio de nossos sentimentos, mas também nos sons reais ou imaginários de nosso tempo e de nosso espaço, dentro de um pertencimento de quem só quem tem a sensibilidade de ver que em uma folha de papel em branco existe o encantamento do convite de fazer coisas nunca antes imaginadas, que não será tão somente uma folha de papel em branco. Ou olhar para o céu e se permitir realizar as várias leituras; em um dia em que nuvens estejam presentes, estas são castelos, reis e rainhas, mas, se a noite chega, poder contar as estrelas que vão surgindo pode ser outra leitura de um mesmo espaço, mas diferente em seus aspectos.

A leitura que entra em nossa infância, com os jogos e brincadeiras de antigamente, das frutas que viravam animais, da galinha que aparecia no terreiro com os seus pintinhos, ou nas histórias de assombração que os mais velhos contavam e que as crianças no seu mundo imaginário "morriam de medo". No castelo que se construía, no circo que chegava e que misteriosamente ia embora, o tempo das férias, dos primeiros amores, da velhice relembrando a juventude, dos livros que chegaram com as suas ilustrações, e as primeiras palavras que começamos a ler, decifrar, decodificar.

A leitura, feita dessa maneira, traz em sua essência o que de fato se propõe na afirmação de Verdini (2007)

\footnotetext{
"Desde que nascemos, diferentes situações nos põem em contato com as palavras. Elas vão sendo ensinadas para que possamos nomear, reconhecer, dar sentido ao mundo onde vivemos e que temos necessidade de aprender a desvendar". (VERDINI, 2007, p.29)
} 
São essas situações do dia-a-dia, como ir ao supermercado, à feira, ir a um culto religioso, fazer uma viagem, assistir a um programa de televisão, que nos põem em contato com as palavras, com os textos e, dessa forma, podemos ir desvendando o mundo onde vivemos, fazendo as várias leituras nas linhas e entrelinhas.

A leitura percebida dessa maneira é o contrário das práticas de leitura que acontecem, na maioria das vezes, no contexto escolar. De fato, a forma como a leitura é trabalhada no contexto escolar fica quase sempre refém de práticas obsoletas, onde $a$ pedagogização desconsidera a natureza específica da leitura, que é o ato comunicacional. (PERROTTI, 2007, p.13)

Ao assumir uma postura que é totalmente contra a pedagogização da leitura, entendo que só uma pedagogia cultural é capaz de resgatar o conhecimento, livrá-lo da pedagogização medíocre e obstusa. "Sem tal pedagogia, não há senão fragmentação, especialização, formalização inócua. E vazio.” (Ibidem)

Essa mudança de postura está intrinsecamente relacionada a práticas de leitura que sejam construídas em outros olhares, outras concepções, porque, num sentido amplo, a leitura desponta junto com a própria existência (VERDINI, 2007), nos convidando a um processo de mobilização de nossa curiosidade, de nossos sentidos, de nosso ser, por completo.

Toda leitura acontece num espaço e este não é vazio nem de matéria, nem de significados (TERALLI, 2007). Esse espaço em que acontece a leitura é a própria vida e, sendo extensiva para os outros campos da ação humana, ocorrerão as trocas significativas, trocas interpessoais, pois ler é uma forma de relação com o mundo, consigo mesmo e com outros modos da cultura escrita (GOZZI, 2007). A respeito dessa forma de entender a leitura, principalmente no contexto escolar, Perrotti (2007) nos instiga fazendo a seguinte pergunta: o que queremos promover nas escolas? Hábitos de leitura ou o ato de ler?

De acordo com esse autor,

Leitura (...), "a decifração mecânica de sinais, é atividade totalmente diversa da ação voluntária sobre a linguagem implicada no ato de ler. Hábitos estão ancorados na repetição mecânica de gestos; atos, na opção, no exercício da possibilidade humana de articular o agir ao pensar, ao definir, ao escolher" (Idem, p.33) 
Assim, é necessário que aconteça uma intervenção nas práticas pedagógicas confinadoras (GOZZI, 2007), pois estamos vivendo em um tempo da pós-modernidade, onde as relações com o conhecimento são outras, não existe mais aquela visão do conhecimento como algo pronto, acabado, imutável. O conhecimento nessa sociedade pós-moderna é algo em construção, mutante, em rede, estabelecendo conexões, construções e desconstruções.

No contexto da escola indígena as práticas de leitura têm sido pautadas em projetos educativos que procuram estabelecer uma forte relação entre a leitura de mundo realizada na vida cotidiana das aldeias e também na presença de alguns tipos de textos (literários e não-literários) oriundos de diversas fontes: jornais, revistas, livros de histórias e livros de assuntos diversos, mapas, atlas históricos e geográficos, revistas em quadrinhos, almanaques . No contexto da própria história da educação escolar indígena, as primeiras experiências com a leitura de textos estão basicamente relacionadas às classes de alfabetização e das primeiras séries do ensino fundamental. Sendo os povos indígenas historicamente povos de tradição oral, com o passar dos tempos, no convívio com outros povos não-indígenas, o contato com diversos suportes de textos foram se fazendo presentes nas aldeias, no convívio com profissionais de instituições governamentais e não governamentais, missionários religiosos entre outros, que faziam uso mais constante da palavra escrita.

Com o passar dos tempos e no fortalecimento da educação escolar indígena, então, materiais diversos (livros, cartilhas, jornais, vídeos, cd's musicais etc...), muitos desses produzidos pelos próprios professores indígenas, passaram a chegar às escolas indígenas, favorecendo o contato das crianças, jovens, adultos e anciãos com esses textos. O documento Referencial Curricular Nacional para as Escolas Indígenas RCNEI, elaborado pelo Ministério da Educação - MEC, com a participação de professores e professoras indígenas de todo o Brasil, no ano de 1998, elucida, na parte que fala das línguas, que todo trabalho de leitural, desenvolvido na escola, deve ter por objetivo a formação de bons leitores. (RCNEI p. 139). Mas, olhando de forma crítica para essa afirmação, o que significa formar bons leitores na escola indígena?

De acordo com o referido documento na escola indígena estão presentes os contos, crônicas, histórias, relatos, receitas, bulas, rótulos, manuais de instrução, regulamentos e listas, questionários, formulários, documentos pessoais, textos de jornais 
e revistas, textos de cartazes, folhetos publicitários e propagandas, textos científicos, projetos e que, a partir da presença desses textos, os professores deverão desenvolver estratégias didáticas para trabalhar de forma plena tais gêneros na sala de aula. E como fica a formação dos bons leitores? Um dos grandes equívocos que temos presenciado na educação escolar indígena é trabalhar tais questões de forma adaptada das escolas não indígenas. Se dentro da escola não-indígena a diversidade de opiniões, leituras e aspectos culturais são infinitos, imagine no território da cultura indígena. Então, a formação desse bom leitor não estaria determinada de forma "receitual", como pressupõe o RCNEI, mas implica entender que a leitura no contexto da educação escolar indígena ocupa uma outra vertente, a do pertencimento a uma comunidade, a um território. A leitura presente não especificamente nos livros, mas a leitura da vida, das lutas históricas, modos de viver e sobreviver.

Nessas questões, o ponto de partida para as práticas pedagógicas nas escolas indígenas, incluindo aqui as práticas de leitura, têm sido identificadas com as experiências do dia a dia, o que nasce no chão da aldeia, a cultura de cada povo, sua especificidade e singularidade para, a partir daí, ir ampliando essa noção do que vem a ser o bom leitor, envolvendo o seu entendimento de mundo, suas experiências enquanto participante da vida de cada povo, sua identidade. Sendo a escola indígena uma instituição que dialoga com outras culturas, outras formas de saberes e conhecimento, isto é, uma escola intercultural, no desenvolvimento de suas práticas pedagógicas irá dialogar com outras formas de leitura, outros tipos de textos literários e não-literários. Assim, o trabalho com a leitura em uma escola indígena, realizado dessa forma, ganha sentido e importância, pois os professores indígenas do Brasil, juntamente com os seus alunos, têm participado da produção de materiais didáticos diversos, sendo, portanto, autores e leitores, e não só leitores, simplesmente.

Para ilustrar tais afirmações, segue alguns trechos de fala de professores indígenas Kiriri Cantagalo, que foram entrevistados e que fizeram parte da pesquisa, para acompanharmos como estes definem o que é leitura, o que corrobora as reflexões trazidas até o presente momento.

\section{Excerto 1}

Assim, quando eu falo de leitura, não é só ler textos nos livros didáticos, e sim ler o nosso ambiente, as árvores, os animais, as plantas, então isso é também um tipo de leitura também. (Nailza, professora Kiriri Cantagalo, 23.04.2012) 


\title{
Excerto 2
}

Ler para mim hoje é fundamental, porque abre novas expectativas, novos horizontes, dá novos ideais, faz a gente viajar, dá novos pensamentos, a partir dela é que a gente começa a mudar nossa visão, nosso modo de ver as coisas e abrange mais nossos conhecimentos. (Jozilene, professora Kiriri Cantagalo, 24.04.2012)

\begin{abstract}
A leitura e a escrita pra nós povos indígenas já vem desde a criança. Essa relação com a leitura pra nós já vem desde o nascer, já vem... é... tá ali no trabalho comunitário, tá ali no... no... batalhão, tá ali ajudando outro parente na roça, tá ali é... envolvendo na... no ritual, na crença nossa, nas convivências com os nossos avós, ali na hora da janta, do almoço, na hora da convivência com a família, isso eu percebo, percebo hoje que a leitura é isso, a relação com a leitura é isso. (Davi, professor Kiriri Cantagalo, 23.04.2012)
\end{abstract}

Indígenas Kiriri Cantagalo se coadunam com as concepções de leitura que foram postas até aqui, mostrando a consciência de que a leitura não é algo que é feito somente nos livros, ampliando para o conceito de leitura enquanto leitura de mundo, da própria aldeia, formada pela fauna e pela flora, a forma de viver e sobreviver do Povo Kiriri Cantagalo. Trata-se da leitura que está presente na cosmologia indígena, ou seja, na visão de mundo de cada povo, que permite ler a interação do índio com o meio ambiente, as relações que são construídas e desconstruídas.

A leitura, para os professores entrevistados, é, principalmente, sua relação com o ambiente, que se desdobra nas árvores que estão presentes no dia a dia desse povo, que são utilizadas em várias atividades da própria aldeia, entre elas a própria cura, os rituais, a alimentação...

Vê-se, então, que a forma de conceber a leitura parte daquilo que conhecem, do que faz sentido para a comunidade, do que é local, indo em direção ao global, para ler outras coisas, fazer outras relações. A partir dessa concepção do que vem a ser leitura, estabelecem-se as relações entre os próprios índios e a relação com os não-índios. Questões importantes são apresentadas, como a leitura dos vários tempos, das estações do ano, de quem chega e quem vai embora, do tempo da fartura e das dificuldades enfrentadas no cotidiano da aldeia. 
A ênfase que é dada pelo professor Davi de que a leitura para os povos indígenas vem desde o nascer, e que se amplia nas várias atividades que são desenvolvidas no dia a dia da Aldeia, mostra que nessa comunidade a leitura é trabalhada dentro dos aspectos da subjetividade, das relações sociais. São formas de ver o mundo, de fazer a leitura de mundo, de poder entender que a leitura se amplia, se constitui a partir dessa relação com o significado que ela tem para um povo indígena.

É uma leitura que acontece em um contexto específico e que tem imbricações com as relações sociais e de poder do Povo Kiriri Cantagalo. Leitura enquanto ato coletivo, de fortalecimento das relações. Leitura presente nas atividades de sobrevivência econômica desse povo, mas também leitura aberta para as questões de religiosidade, que é a leitura que pode ser feita dos rituais, da crença, da valorização dos mais velhos no momento de ouvir os conselhos, aprender com as experiências. Enfim, a leitura enquanto ato solidário, inclusive de poder partilhar com o outro o momento do almoço, da janta, da convivência com a família.

Aprofundando tais questões fica evidente de que as concepções de leitura evidenciadas pelos professores e professoras Kiriri Cantagalo perpassa pelo sentido do pertencimento, da construção e afirmação de uma identidade, pela valorização da cultura, pelas relações com outros aspectos presentes no dia a dia desse povo, a exemplo de sua organização social, suas lutas, conquistas, a forma como organiza os conhecimentos e saberes e como lida com tudo isso.

\subsection{PROFESSORES INDÍGENAS KIRIRI CANTAGALO: SEUS PROCESSOS EDUCACIONAIS E PRÁTICAS DE LEITURA}

Para compreendermos as práticas de leitura dos professores indígenas Kiriri Cantagalo, que foi objeto de estudo do trabalho de pesquisa no meu mestrado, é necessário apresentar a relação deste Povo com as primeiras experiências educacionais, uma vez que são nessas trajetórias que tais práticas de leitura são desenvolvidas.

Em conversa com os professores e professoras indígenas Kiriri Cantagalo, a respeito do início da educação no meio desse povo, foi relatado que a primeira experiência educacional institucionalizada foi através da Escola Municipal Indígena Marechal Rondon. Essa escola deu início às suas atividades no ano de 1976, e está localizada na Aldeia Cantagalo. Ela foi construída de palha e barro pelas pessoas da 
aldeia, lideradas pelo Cacique Lázaro e Conselheiros, ou seja, representantes de cada aldeia que, juntamente com o cacique, administram o território indígena. Foi a primeira escola entre os Kiriri Cantagalo. As lideranças se mobilizaram e conseguiram um professor da Fundação Nacional do Índio - FUNAI, de Brasília. Funcionava com 50 alunos nos dois turnos: matutino e vespertino, com classes multisseriadas, e havia muitos casos de defasagem idade/série, sendo que até o ano de 1997 houve somente três professores da FUNAI.

Em 1998 houve o processo de retomada do Território Indígena e do povoado de Araçás. A Escola Marechal Rondon foi implantada no Araçás, em um prédio com outra estrutura física, pois esta escola era feita de alvenaria, funcionando nos dois turnos matutino e vespertino - com alunos de $1^{\mathrm{a}}$ a $4^{\mathrm{a}}$ série, divididos em quatro turmas. No ano de 2002, a Escola Municipal Indígena Marechal Rondon foi transformada no Núcleo Municipal de Educação Indígena Marechal Rondon. Foi colocada uma direção escolar para gerenciar e administrar as escolas em anexo, que ficam nas Aldeias de Segredo, Cajazeira, Baixa da Cangalha e Baixa do Juá. Com a necessidade de implantar o ensino de $5^{\mathrm{a}}$ à $8^{\mathrm{a}}$ série, pois existia uma reivindicação por parte das lideranças indígenas Kiriri Cantagalo, e as condições eram favoráveis, uma vez que existia um quantitativo de professores indígenas que tinham o Magistério e que todos os anos muitos alunos indígenas ao concluírem seus estudos a nível de $4^{\mathrm{a}}$ série, iam estudar nas escolas de Banzaê ou nos povoados circunvizinhos às aldeias, onde esses estudantes enfrentavam uma realidade diferente, muitos deles eram discriminados e maltratados pelos exposseiros, como o aumento substancial do consumo de álcool e outros fatores.

No ano de 2009 acontece a implantação do ensino de $5^{\mathrm{a}}$ a $8^{\mathrm{a}}$ série no Núcleo Municipal de Educação Indígena Marechal Rondon, sendo que para isso a Secretaria Municipal de Educação de Banzaê faz a construção de um pavilhão contendo duas salas de aula, permitindo, dessa forma, que os alunos tivessem espaço físico adequado para os seus estudos. O Núcleo Municipal de Educação Indígena Marechal Rondon passou a funcionar nos três turnos com cerca de 260 alunos, além dos anexos de Cajazeira, Segredo, Baixa da Cangalha e Baixa do Juá. Assim, o ensino ministrado passa a ser de $1^{\text {a a }} 8^{\text {a }}$ série, pois a Educação Infantil era ofertada para o Povo Kiriri Cantagalo em escolinhas mantidas pela Igreja Católica Romana, através das freiras da Congregação Italiana das Filhas de São José, sediada em Cícero Dantas - Bahia. 
Após a implantação do Ensino Fundamental de $5^{\mathrm{a}}$ a $8^{\mathrm{a}}$ série na Aldeia de Araçás o Povo Kiriri Cantagalo, as lideranças indígenas, juntamente com os professores e professoras indígenas e demais pessoas das comunidade, reivindicaram junto aos órgãos competentes da Educação do Estado da Bahia a implantação do Ensino Médio como extensão do Colégio Estadual Flaviano Dantas do Nascimento localizado no Município de Banzaê. Inicialmente foi implantada uma turma da $1^{\text {a }}$ série do Ensino Médio, com um total de 35 alunos matriculados e com a proposta de que nos anos subsequentes fossem implantadas a $2^{\mathrm{a}}$ e $3^{\mathrm{a}}$ série do referido curso. As inquietudes por uma educação escolar indígena de qualidade fez com que a mobilização das lideranças indígenas Kiriri Cantagalo organizasse um documento reivindicatório solicitando ao Secretário da Educação do Estado da Bahia a estadualização de todas as escolas municipais indígenas Kiriri Cantagalo.

Assim, no dia 20 de maio de 2011, foi publicado no Diário Oficial do Estado da Bahia a Portaria de no 4129/2011, estadualizando o Núcleo Municipal de Educação Indígena Marechal Rondon, passando a chamar-se Colégio Estadual Indígena Florentino Domingos de Andrade, com os anexos das Aldeias Cajazeira, Araçás, Segredo, Baixa da Cangalha e Baixa do Juá, e ofertando a Educação Infantil, Ensino Fundamental ( $1^{\circ}$ ao $9^{\circ}$ ano), Ensino Médio e Educação de Jovens e Adultos.

É dentro desse contexto que as práticas de leituras dos professores e professoras Kiriri Cantagalo são desenvolvidas. Mas como é que acontece esse desenvolvimento?

Os trabalhos de observação nas salas de aula dos três professores envolvidos na pesquisa evidenciaram que as práticas de leitura desenvolvidas por eles estavam voltadas para os aspectos relacionados à concepção de leitura apresentados por cada um deles e já demonstrado neste texto. Assim, os professores demonstraram que tais práticas são desenvolvidas com os seus alunos partindo das vivências desses através de diálogos, incentivando os alunos a fazerem leituras das coisas que estão perto, tanto no grupo indígena quanto em seu território como um todo.

Entendo que essa leitura deveria fazer uma relação das questões voltadas para a cultura indígena, mas também para o mundo do não-índio, uma vez que o contato com as pessoas que não são índias e que vivem nas comunidades/povoados e cidades no entorno na Terra Indígena Kiriri é muito intenso e que a educação diferenciada 
pressupõe apropriação de conhecimentos de outras culturas, para além da cultura indígena.

As práticas de leitura também são vistas pelos professores e professoras Kiriri Cantagalo como oportunidade de poder mostrar aos alunos algo a mais, envolvendo a sua criatividade, não só fazendo a leitura em seu aspecto teórico, mas estabelecendo relações com questões da vida cotidiana, de como esses conhecimentos e saberes estão conectados. No desenvolvimento de tais práticas, as dificuldades apresentadas pelos professores e professoras envolvidas na pesquisa são na garantia de um espaço de formação para o trabalho com a leitura em sala de aula e na escola, pois todas as atividades desenvolvidas são atividades pesquisadas em livros diversos, não havendo uma formação específica que amplie as metodologias referentes ao ensino da leitura, permitindo uma diversificação de estratégias de leitura. Os professores e professoras percebem a importância desse referencial teórico para as questões da leitura, se mostram receptivos a avançar nas questões de práticas de leitura, pois assim poderiam usufruir de atividades diversificadas acerca do trabalho da leitura em sala de aula.

A presença dos materiais de leitura: livros, revistas, jornais, gravuras, letras de música, artesanato, filmes foram utilizados pelos professores pesquisados. Os livros utilizados pertencem em sua maioria ao acervo do Programa Nacional de Biblioteca Escolar - PNBE, do Ministério da Educação, que a escola recebeu ao longo dos últimos anos, além do livro Leituras Kiriri: Histórias do nosso povo, que foi produzido por um grupo de professores e professoras Kiriri durante a $1^{\text {a }}$ Turma do Magistério Indígena da Bahia e que tem servido de suporte para as práticas de leitura entre os alunos do ensino fundamental.

Ainda na observação que fiz das aulas, foi constatado que os professores e professoras indígenas Kiriri Cantagalo fazem valer em suas práticas o que eles entendem por leitura: a leitura de mundo, a leitura da vida, antes de se fazer a leitura da palavra. Presenciei uma valorização da cultura indígena no desenvolvimento de tais práticas, pois eram a partir de elementos dessa cultura que os professores iniciavam as suas aulas, sempre através de uma história, um canto, um relato. Esses professores e professoras começaram a trazer para a sala de aula jornais, revistas, filmes e outros tipos de livros, fazendo uso desses portadores de texto em suas aulas. 
No início das observações as práticas de leitura desses professores e professoras aconteciam de forma tímida, mas com o passar do tempo começaram a trocar experiências entre si e avançaram no vencimento de obstáculos, inclusive na preocupação de desenvolver projetos de incentivo à leitura. Os gêneros literários mais presentes nessas práticas eram os contos, as lendas, cantiga popular, fábulas, poemas, paródia, anúncio publicitário, entrevista. Desses, os que tiveram maior ênfase foram os contos, as lendas e os poemas. A receptividade dos alunos e alunas acontecia de forma positiva, pois estes, além de se interessarem pelas práticas de leitura que os professores estavam desenvolvendo nas salas de aula, emitiam opiniões, faziam as atividades propostas. Houve uma integração dos outros componentes curriculares e, assim, as práticas de leitura não ficaram restritas somente às aulas de Português. Os professores de Ciências, Artes e Matemática começaram a desenvolver atividades em suas aulas envolvendo práticas de leitura.

As práticas de leitura desenvolvidas por esses professores envolvidos na pesquisa permitiram aos mesmos a possibilidade de, nos anos subsequentes, desenvolver tais práticas de forma mais sistematizada e aprofundada, pois esse foi o entendimento dos respectivos professores que, após uma avaliação das atividades desenvolvidas, perceberam os aspectos que precisavam ser melhorados, formas de enriquecer tais práticas, tendo como ponto de partida as que foram desenvolvidas e a necessidade de envolver a escola como um todo, partilhando com os pais, funcionários e comunidade, envolvendo as manifestações culturais do povo Kiriri Cantagalo, a exemplo do Toré e da Zabumba, além dos elementos da música, desenho, teatro, fotografia. Outra questão que foi muito importante no desenvolvimento dessas práticas foi a grande vontade que os alunos e alunas demonstraram em registrar as histórias, contos e lendas dos seus antepassados. Observamos que esses alunos se encantavam quando eles mesmos contavam para os demais colegas as histórias que tinham pesquisado em sua comunidade, no meio de sua família, de seus avós. Essa vontade em ver registrado, através de livros escritos e produzidos por eles mesmos, ou outras formas de registro, põe em evidência a importância das práticas de leitura desenvolvidas pelos professores observados.

A partir desta reflexão, fica evidente que as práticas de leitura realizadas pelos professores e professoras indígenas Kiriri Cantagalo são importantes para o seu 
desenvolvimento educacional e comunitário. Os professores e professoras pesquisados trazem em suas vidas profissionais inquietações, preocupações, medos, desafios a serem superados. Que caminhos teriam então esses professores a trilhar? Seria imaturidade de nossa parte apresentar soluções para os problemas apresentados. Mas, voltando à questão do que vem a ser uma escola indígena, essa escola tem que estar a serviço de sua comunidade, de seu povo, desenvolvendo atividades bem planejadas, pensadas de forma coletiva, na busca de resultados satisfatórios. É o entendimento de que um trabalho consistente de práticas de leitura como este iniciado pelos professores e professoras desenvolva nos alunos diversas capacidades, e que lendo o mundo, participando de forma ativa, vivenciando no seu dia a dia vá se constituindo enquanto leitor, entendendo a leitura de forma ampla, e não como algo restrito somente à unidade escolar. É a leitura de mundo, como enfatiza a Professora Nailza, leitura do mundo indígena com seus valores, diferenças, tradições, saberes e conhecimentos, em permanente diálogo com outras culturas, com os seus desafios, certezas, incertezas e diversidade.

Dessa maneira, é preciso descortinar novos horizontes, como enfatizou a Professora Jozilene, mas entendendo onde se está e onde se deseja chegar, entendendo que práticas de leitura, quando são desenvolvidas, permitem um trabalho consistente no contexto escolar fazendo conexões com o contexto não-escolar.

É preciso lembrar que a leitura e a escrita se fizeram presentes nas comunidades indígenas do Brasil não há muito tempo. As dificuldades que os povos indígenas no Brasil têm enfrentado para desenvolver seus projetos educacionais em suas escolas são inúmeras: falta de recursos materiais e financeiros para aporte dos projetos, estrutura física da maioria das escolas comprometedora, falta de um desenvolvimento de políticas públicas que garantam aos povos indígenas o acesso aos bens culturais da humanidade, dentre outros. Nas questões de projetos de leitura, isso tem sido desafiador, mas tais desafios também animam para continuar o processo de luta e de conquistas.

\section{CONCLUSÃO}

No desenvolvimento do trabalho de pesquisa, constatei que os contextos diversos nesse universo da cultura Kiriri Cantagalo permitem diferentes leituras e que o 
fortalecimento de sua identidade enquanto professores indígenas corrobora com o desejo destes em desenvolver práticas de leitura diversificadas. Seria, então, uma forma diferente de caminhar, pois são diversos processos que se inter-relacionam, processos esses que vão desde a forma como esse povo foi constituído, os primeiros contatos com a população não-indígena nos séculos XVI e XVII, as influências de vários grupos religiosos cristãos e não cristãos, a organização político-administrativa, a espiritualidade, a relação com o processo de retomada de seu Território no Século XX, entre outros. Esses elementos nos remetem à compreensão de que nessas práticas de leitura existem fatores intrínsecos e extrínsecos, e que um estudo mais aprofundado ajuda a compreender e também contribuir.

Concluindo, é importante enfatizar que não se pode medir a educação escolar indígena e suas práticas pedagógicas e de leitura a partir do que acontece na educação dos não indígenas. Isso tem sido um grande desafio para os professores e professoras indígenas Kiriri Cantagalo e demais povos indígenas da Bahia e do Brasil que, em tempos de IDEB e de Prova Brasil, são cobrados a darem conta da elevação do índice de desenvolvimento de suas escolas, da qualidade da educação desenvolvida nas escolas indígenas. Nesse sentido, os povos indígenas saíram das influências e tutela dos missionários para serem reféns de órgãos oficiais de ensino e agências de organismos internacionais de financiamento da educação. Afinal, ter qualidade nas práticas pedagógicas e de leitura desenvolvidas pelas escolas indígenas não pode estar atrelado às práticas educacionais hegemônicas, neoliberais, que tanto têm influenciado a educação escolar no Brasil.

\section{REFERÊNCIAS}

BRASIL. Ministério da Educação. Referencial Curricular Nacional para as Escolas Indígenas. Brasília: MEC, 1998.

FUNAI. Fundação Nacional do Índio. Relatório Técnico: Povo Indígena Kiriri Cantagalo. Paulo Afonso - Bahia. 2010.

GOZZI, Rose Mara. Espaços de leitura articulados: a escola, a casa, a comunidade. In: Espaços de leitura. Ministério da Educação. Brasília: 2007. 
PERROTTI, Edimir. Proposta Pedagógica. In: Espaços de Leitura. Ministério da Educação. Brasília: 2006.

TARALLI, Cibele Haddad. Espaços de leitura: Salas de leitura/ Bibliotecas Escolares. In: Espaços de leitura. Ministério da Educação. Brasília: 2007.

VERDINI, Antônia de Sousa. Espaços de leitura na escola: sala de aula/ cantos de leitura. In: Espaços de leitura. Ministério da Educação. Brasília: 2007.

RECEBIDO EM: 01 de novembro de 2012

APROVADO EM: 12 de dezembro de 2012 